\title{
A INDÚSTRIA CULTURAL E A DES/RE/CONSTRUÇÃO DAS ESTEREOTIPIAS DE FAMÍLIAS NA FORMAÇÃO DE CONCEITOS DOCENTES
}

\author{
LA INDUSTRIA CULTURAL Y LA DES/RE/CONSTRUCCIÓN DE LAS \\ ESTEREOTIPIAS DE FAMILIAS EN LA FORMACIÓN DE CONCEPTOS \\ DOCENTES
}

\section{THE CULTURAL INDUSTRIES DES/RE/CONSTRUCTION OF STEREOTYPES FAMILIES IN TRAINING CONCEPTS TEACHERS}

\author{
Isaias Batista de Oliveira JÚNIOR ${ }^{1}$ \\ Dirce Aparecida Foletto de MORAES ${ }^{2}$ \\ Renata Maria COIMBRA ${ }^{3}$
}

RESUMO: Conceituar família na contemporaneidade é um exercício que exige profundas reflexões, visto que a indústria cultural através da mídia pulveriza e torna visível uma série de experiências biográficas e modelos organizacionais que contribuem para aprofundar e ampliar os estigmas reforçando estereotipias. Pensando na problematização do conceito de família temos como objetivo deste estudo compreender como a indústria cultural contribui na formação do conceito de família na visão de alunos do curso de pedagogia como condição de sua futura atuação profissional. Participaram da investigação alunos do primeiro ano do referido curso de uma Universidade Pública do Estado do Paraná, através de debates acerca do conceito de família utilizando como estratégias textos, fontes disponíveis na rede mundial de computadores e propagandas televisivas. Concluímos que a visão dos sujeitos da pesquisa aponta para uma visão clássica de família, baseada em características definidoras. É necessário problematizar a realidade das famílias na contemporaneidade no processo formativo destes indivíduos e a complexidade dos fatores que interferem no seu conceito de família, para tanto, ela deve ser compreendida historicamente e analisada em suas especificidades através da adoção de determinados pressupostos pedagógicos.

PALAVRAS-CHAVE: Escola. Mídia. Conceitos. Famílias.

RESUMEN: Conceptualizar familia en la contemporaneidad es una actividad que exige profundas reflexiones, considerando que la industria cultural a través de los medios de comunicación esparce y hace visible una serie de experiencias biográficas y modelos organizacionales que contribuyen para profundizar y ampliar los estigmas

\footnotetext{
${ }^{1}$ Professor Colaborador na Universidade Estadual do Paraná - UNESPAR. Doutor em Educação pela Universidade Estadual Paulista Júlio Mesquita Filho. Email: jr_oliveira1979@ hotmail.com

2 Doutoranda em Educação pela Universidade Estadual Júlio Mesquita Filho - FCT. Mestre em Educação. Professora do Departamento de educação da Universidade Estadual de Londrina - UEL. Email: dircemoraes2007@gmail.com

${ }^{3}$ Doutora em Psicologia escolar e do desenvolvimento humano pela Universidade de São Paulo (USP). Professora do Departamento de Educação e do Programa de Pós-graduação em educação da UNESP / Presidente Prudente (Mestrado e Doutorado) ; Pós-doutorado na área da Sociologia da Infância, realizado no IEC - Universidade do Minho. Email: coimbralibor@uol.com.br
} 
reforzando estereotipias. Pensando en la problematización del concepto de familia tenemos como objetivo en este estudio comprender como la industria cultural contribuye en la formación del concepto de familia en la visión de alumnos de la carrera de pedagogía como condición para su futura actuación profesional. Participaron de la investigación alumnos del primer año de la referida carrera de una Universidad Pública del Estado de Paraná, por medio de debates sobre el concepto de familia, utilizando como estrategias textos, fuentes disponibles en la red mundial de computadoras y propagandas televisivas. Concluimos que la visión de los sujetos de la investigación lleva para una visión clásica de familia, basada en características definidoras. Es necesario problematizar la realidad de las familias en la contemporaneidad en el proceso formativo de estos individuos y la complexidad de los factores que interfieren en su concepto de familia, para tanto, ella debe ser comprendida históricamente y analizada en sus especificidades a través de la adopción de determinadas premisas pedagógicas.

PALABRAS CLAVE: Escuela. Medios de comunicación. Conceptos, Familias.

ABSTRACT: Conceptualizing family in contemporary society is an exercise that requires deep reflection, as the cultural industry through the media sprays and brings up a series of biographical experiences and organizational models that contribute to deepen and broaden the stigmata reinforcing stereotypes. Thinking about the family concept of questioning we aim of this study to understand how the cultural industry contributes to the family of concept formation in view of pedagogy students in the program as a condition of their future professional activities. Students of the first year of the mentioned course of a Public University of the State of Parana participated in the research, through debates about the concept of family using as strategies texts, sources available in the internet and in television advertisements. We conclude that the research subjects view points to a classic vision of family, based on defining characteristics. It is necessary to question the reality of families in contemporary times in the training process of these individuals and the complexity of the factors that interfere with its concept of the family, therefore, it must be understood historically and analyzed in their specificity by adopting certain pedagogical assumptions.

KEYWORDS: School. Media. Concepts. Families.

\section{Re/pensando famílias na contemporaneidade}

Conceituar família na contemporaneidade é um exercício que exige profundas reflexões, visto que a indústria cultural através da mídia pulveriza e torna visível uma série de experiências biográficas e modelos organizacionais que contribuem para aprofundar e ampliar os estigmas, reforçando estereotipias.

Em nosso meio social há vários problemas na socialização, mas dois especiais são questionáveis: o primeiro é que a mídia tem dono e é paga e o fato de não termos apenas telespectadores, mas também anunciantes, seu conteúdo informativo tem que respeitar o perfil do público ou forjar um perfil para ele. O segundo problema é o 
entendimento da existência de um homem/mulher de entendimento mediano e para esse modelo abstrato de recepção as mensagens precisam ser selecionadas, aparadas, arredondadas e/ou modificadas (MELLO, 2001, SETTON, 2002b).

Esta cultura de massa ao circular informação, entretenimento e propaganda também transmite em seu bojo valores e padrões de conduta diversificados. A formação deste capital social sustenta-se num jogo de linguagem, que perpassa por toda a sociedade, transpõe os muros escolares refletindo em seus ritos por meio da apreensão da crença que o sustenta, das coisas materiais e simbólicas que nele se geram, do ato explicativo, do tornar necessário, da subtração, do arbitrário e não motivado, ou seja, são atos produtores de como geralmente se julgar, reduzir ou des/re/construir (BOURDIEU, 1989).

Considerar o caráter pedagógico da cultura de massa é salientar que a ampla circularidade dos bens culturais juntamente com a difusão das informações contribui para o surgimento de novas formas de interação educativa (SETTON, 2002a, 2002b).

Essas disposições são duradouras, o que acarreta toda a espécie de efeitos de histerese (atraso e defasagem) e nos habilita a pensar que o processo de constituição das identidades sociais no mundo contemporâneo impõe à escola uma nova compreensão de família na atualidade, uma vez que, "o modelo" heteronormativo", padronizado, assimilado como sendo verídico, deixou há tempos de ser um arquétipo predominante, devido aos novos arranjos familiares (BOURDIEU, 2003).

De tal maneira que a nomeação singular de família, seja preterida por seu uso no plural "em virtude do reconhecimento de uma extensa gama de formações familiares, decorrentes de novas combinações de estruturas e valores (recasamentos, casais homossexuais, famílias monoparentais, uniões estáveis e tantas outras)". (BRANDÃO; CANEDO; XAVIER, 2012, p. 199).

Tal cuidado é premente, pois o cotidiano escolar é um dos espaços em que se reiteram práticas excludentes daqueles/as que desatendem os padrões normativos, ao privilegiar em seus ritos escolares um estilo particular de exercício de paternidade/maternidade e que poderá enfraquecer a autonomia e a liberdade de pais e mães, propagado pela cultura de massa. Essa questão é marcante em eventos como "dia

${ }^{4}$ Constituído por padrões rígidos de comportamentos, identidades de gênero delimitadas, papéis sociais preestabelecidos que recaem sobre "o homem" e "a mulher" e ditam regras de como ser e estar em consonância com a norma. A heteronormatividade, embora pouco discutida, na prática se faz presente em todas as esferas sociais, a incluir a igreja, a escola, a família, a mídia, etc. (OLIVEIRA JR, MAIO, 2014). 
das mães”, “dia dos pais", “dia da família”, "dia da/o avó/ô”, reuniões de pais/mães, etc. (CARVALHO, 2004).

A escola necessita reconhecer que no século XXI a família surge como um grupo natural onde os indivíduos são unidos por uma tripla relação: "por um lado a geração, que dá os componentes do grupo; por outro as condições de meio que postula o desenvolvimento dos jovens e que mantêm o grupo, enquanto os adultos geradores asseguram essa função" (LACAN, 1981, p. 10), bem como pela subjetividade que torna o relacionamento humano tão rico e envolvente, conferindo ao sistema familiar características próprias (HINTZ, 2006).

A família deve ser compreendida como um gênero permeado por várias espécies, "e mesmo no que consideramos "nosso" modelo mais estável e mais familiar, existem tantas subespécies! Os "progressos da genética libertam ou aceleram nossa imaginação". (DERRIDA, ROUDINESCO, 2004, p. 53).

Vemos nessas entidades "não somente um agregado mais vasto de pares biológicos, mas sobretudo um parentesco menos conforme aos laços naturais de consanguinidade". (LACAN, 1981, p. 12).

A família se mostra uma estrutura:

[...] profundamente complexa, da qual mais do que um ponto se esclarece melhor pelas instituições positivamente conhecidas da família antiga do que pela hipótese duma família elementar a qual não se encontra em parte alguma. Isto não é dizer que seja demasiado ambicioso procurar nesta forma complexa um sentido que a unifica e talvez dirija a sua evolução. Este sentido aparece precisamente quando, à luz deste exame comparativo, se apreende a modificação profunda que conduziu a instituição familiar à sua forma atual; reconhece-se ao mesmo tempo que é preciso atribuí-la à influência prevalente que tem aqui o casamento, instituição que se deve distinguir da família (LACAN, 1981, p. 13).

Nesse contexto, é válido reiterar que a família passou por significativas transformações, "tanto internamente, no que diz respeito a sua composição e as relações estabelecidas entre seus componentes, quanto às normas de sociabilidade externas existentes, fato este que tende a demonstrar seu caráter dinâmico" (OLIVEIRA, 2009, p. 23). Todas essas evoluções em nossos costumes contemporâneos não são passíveis de compreensão se desprezamos esse prodigioso crescimento do sentimento da família (ÀRIES, 1981).

Encontramo-nos frente a uma série de formas de ser e estar família, que estão em contradição direta com as até agora admitidas como únicas e verdadeiras. Pensar na 
visão de família através da escola e da mídia demanda uma análise dinâmica entre tais instituições, criada pela relação que seus sujeitos constroem em suas ações e experiências, objetivas e subjetivas, que mantêm uns com os outros por "uma gama variada de imagens, códigos e conteúdos que se organizam coerentemente na forma de um sistema integrado de símbolos interdependentes aos valores escolar, familiar e midiático" (SETTEN, 2002a, p. 113).

Tomando como pressuposto a visão de exemplares de Lomônaco (1996; 2001), a ser aprofundada na análise dos dados, assim determinada por possuir papel predominante na categorização, presumivelmente porque são mais acessíveis que a descrição sumária, podemos conceituar família pautados em Engels (1984) e Hironaka (2011) como sendo uma instituição não singular, mas sim plural, e essa multiplicidade não se refere simplesmente ao ato de nomear cada membro que a compõe, mas expressa as ideias que se tem além da consanguinidade próxima/distante, igual/desigual, que servem de evidência para um sistema inteiramente organizado e capaz de expressar centenas de diferentes relações de parentesco que permitem um indivíduo organizar-se como família. Neste tempo em que até o milênio muda, muda a família, muda o seu cerne fundamental, muda a razão de sua constituição, existência e sobrevida, mudam as pessoas que a compõem, onde os sujeitos dessa relação passam a ter a coragem de admitir que se case principalmente por amor, pelo amor e enquanto houver amor.

\section{CAMINHOS DA PESQUISA}

Pensando na problematização do conceito de família atribuído pela mídia sustentamos este estudo na necessidade de (re)conhecer a visão que estudantes de licenciatura em pedagogia possuem sobre famílias na contemporaneidade, sendo imprescindível definir estratégias que possibilitem flexibilização de olhares, destes futuros educadores, para essas organizações, com o intuito de estabelecer uma ética relacional onde os sujeitos envolvidos possam expressar suas singularidades cognitivas, afetivas, históricas, culturais e sociais.

Partindo desses pressupostos o presente estudo tem como objetivo compreender como a indústria cultural contribui na formação do conceito de família na visão de alunos do curso de pedagogia como condição de sua futura atuação profissional. A partir do objetivo central desdobram-se os objetivos específicos, quais sejam: caracterizar a família na contemporaneidade, delinear a visão conceitual que alunos do 
curso de pedagogia possuem sobre família; apontar a integralização entre escola e famílias organizadas em modelos não convencionais como pressuposto de uma gestão democrática.

Este estudo é parte avaliativa como conclusão da disciplina de Aprendizagem de Conceitos e Tecnologias realizada em nível de Stricto Sensu, cujos autores eram alunos.

Os sujeitos da pesquisa foram constituídos por 20 alunos do total de 77, do $1^{\circ}$ ano do curso de Licenciatura de uma Universidade Estadual do norte do Paraná, onde um dos autores da pesquisa leciona. $\mathrm{O}$ número excedente de alunos direcionou-se a outras oficinas com temáticas distintas.

O tema "Conceitos: família, indústria cultural e mídia" foi introduzido como conteúdo curricular na disciplina de Educação e Tecnologia, pelo período de um mês, no primeiro semestre de 2014, o que compreende efetivamente oito horas/aula, organizado em quatro encontros.

O princípio metodológico do conteúdo deu-se com discussões com os alunos sobre a temática, seguido da solicitação para que cada um redigisse tais conceitos de acordo com seu entendimento. Tal proposta tinha como intenção o levantamento dos conhecimentos iniciais dos discentes sobre os conceitos.

Posteriormente utilizou-se três propagandas midiáticas cuja atmosfera permeia famílias para transmissão aos alunos. Dentre os vídeos escolhidos um correspondia a uma propaganda de supermercado onde famílias heteronormativas faziam $\operatorname{compras}^{5}$, um segundo sobre determinado condomínio residencial que adota o mesmo modelo central de família ${ }^{6}$ e por fim um terceiro de uma grande marca de cosméticos que aborda as mais distintas formas de maternidade, dentre elas a monoparentalidade e a homoafetividade ${ }^{7}$.

Seguido a essas atividades os alunos precisavam expor a definição de seus conceitos aos demais colegas.

Como constructo para a formação de novos conceitos sugeriu-se a leitura do texto "Família e escola: um novo (re)pensar e (re)agir pedagógico" de Oliveira Jr; Maio (2013), pesquisas na internet e reelaboração do conceito por meio de uma atividade colaborativa com o uso do editor de texto do Google Drive, na qual deveriam definir os conceitos e discutir como a indústria cultural caracteriza família na atualidade. Posterior

\footnotetext{
${ }^{5}$ Disponível em <https://www.youtube.com/watch?v=q-BDCP BNW0 $>$. Acesso em: 03 mai. 2014.

${ }^{6}$ Disponível em $\langle$ https://www.youtube.com/watch?v=U582U2WXGPY $>$. Acesso em: 03 mai. 2014

${ }^{7}$ Disponível em <https://www.youtube.com/watch?v=-w5VH7SnCDk>. Acesso em: 03 mai. 2014.
} 
a esta proposta, como requisito não obrigatório sugeriu-se aos alunos que tais conceitos fossem transpostos a um blog pessoal de forma individualizada.

A sequência didática aqui apresentada buscou uma diversificação de estratégias e recursos na tentativa de possibilitar diferentes experiências na construção do conceito e a superação do paradigma da instrução como única alternativa de ensino na universidade.

Buscou-se a compreensão dos textos elaborados mediante a análise de conteúdo, caracterizada como sendo aquela em que se constitui de uma série de técnicas e instrumentos empregados na análise e interpretação de dados. O emprego desta metodologia tem o intuito de efetivar uma leitura crítica e aprofundada destes materiais, que possam nos levar a uma descrição de valores, significados, motivações e crenças que permeiam os processos de conceituação de famílias através da mídia (LARA \& MOLINA, 2011).

A inferência sobre as condições de produção e recepção não se sustenta apenas na compreensão do fenômeno em si, mas sim dos esquemas valorativos que orientaram a construção de discursos em torno desse, que poderão contribuir para a (re)significação do papel do educador, tanto em seu processo formativo, quanto em sua atuação profissional (LARA \& MOLINA, 2011).

Para Lomônaco (2001) existem quatro tipos de explicar estes conceitos: visões clássica, prototípica, dos exemplares e teóricas.

A visão clássica pressupõe que hajam atributos ou traços necessariamente comuns a todos os membros de uma categoria que abstraídos vem a "formar uma representação mental que sumariza os aspectos partilhados por todos os subconjuntos de uma classe. É esta representação mental que damos o nome de conceito" (LOMÔNACO, 2001, p.161-62).

A visão prototípica defende a formação do conceito através da abstração dos atributos mais frequentes entre os membros de uma determinada categoria. Tem como pressuposto a negação da existência de atributos definidores de conceitos naturais e acredita que, "a partir desses atributos característicos ou mais frequentes, o indivíduo forma uma representação mental denominada protótipo" a ser utilizado como critério de inclusão, caso o item seja suficientemente similar ao protótipo, ou exclusão de itens na respectiva categoria, pela não similaridade (LOMÔNACO, 2001, p. 162). 
"A visão dos exemplares, por sua vez, acredita que, ao invés da formação de um protótipo, as categorias são representadas por um ou alguns exemplos individuais representativos" (LOMÔNACO, 2001, p. 162).

$\mathrm{Na}$ visão teórica o conceito passa a ser visto não mais isoladamente, mas como constituinte de uma rede relacional da qual deriva seu significado.

\begin{abstract}
A esta rede de relações é atribuída o nome de "teoria". A palavra teoria aparece entre aspas uma vez que, nesta visão de conceitos, o termo refere-se comumente a relações estabelecidas pelo senso comum. [...] o conhecimento que as pessoas têm do mundo, quer aquele adquirido através da educação formal (e que, frequentemente, implica na aprendizagem de teorias científicas), quer aquele adquirido de maneira informal e acidental (e que, frequentemente difere, em maior ou menor grau, do conhecimento científico) é considerado como a teoria do sujeito a respeito de aspectos do seu mundo" (p. 162).
\end{abstract}

Feita a caracterização teórica de cada visão descrita por Lomônaco (1996; 2001), sustentaremos nossas análises nos discursos produzidos pelos sujeitos da pesquisa pautados nestas visões.

\title{
Apresentando algumas considerações
}

Embora fosse componente do conteúdo da disciplina a conceituação de mídia, indústria cultural e família, como fizemos até o presente momento, iremos nos ater apenas a discussão sobre o último conceito.

Delimitaremos as discussões aos escritos referentes à definição produzida pelos participantes da pesquisa ao final do trabalho, os quais nomearemos os participantes em Grupo 01, Grupo 02, Blog 01 e Blog 02.

O Grupo 01 considera família como sendo:

"[...] o conjunto de pai, mãe e filhos, pessoas do mesmo sangue, descendência ou linhagem [... ]. Entende-se então como família a junção de pessoas do mesmo sangue com grau de parentesco. Pai, mãe, filhos, irmãos, primos, tios, tias, sobrinhos, podendo ser considerado os laços afetuosos como critério para inclusão na família. Família é um conjunto de pessoas que possuem grau de parentesco entre si e vivem na mesma casa formando um lar. Uma família tradicional é normalmente formada pelo pai e mãe, e por um ou mais filhos".

A autora do Blog 01 comunga da mesma visão ao definir família como sendo aquela:

"[...] compreendida pelo grupo familiar onde nascemos, e é essa família que nos traz uma base para a cidadania e para que sejamos 
indivíduos presentes e participantes na sociedade onde vivemos, mais ela abrange também àquela que viemos a constituir na fase adulta através do casamento e uniões afetivas".

A autora do Blog 02 defende o mesmo ponto de vista: "A família se configura em um conjunto de pessoas que possuem grau de parentesco entre si”.

Muito recorrente em nossa sociedade, inclusive na escola, essa visão clássica ao considerar "que os conceitos são formados através da abstração de atributos comuns a todos os membros de um grupo de coisas, eventos ou pessoas" conceitua família baseado no modelo nuclear sustentado na consanguinidade, colateralidade $\mathrm{e}$ descendência, sendo que, estes subsídios são precários na conceituação de famílias na contemporaneidade (LOMÔNACO, 1996, p. 51).

Esta representação do conceito de família consiste numa descrição sumária de uma classe inteira: por exemplo, ao representar o conceito de família, resume-se em uma única representação características partilhadas por todas as famílias. Assim, ela é resultante de três características essenciais: primeiramente de um processo de abstração, não corresponde a nenhum exemplo específico e aplica-se a todas as formas de família possíveis (LOMÔNACO, 1996, 2001).

Em segundo lugar essas características representativas do conceito de família são individualmente necessárias e conjuntamente suficientes para defini-la. Por exemplo: pai, mãe, são características singulares necessárias para que toda entidade que possua esse conjunto de características seja família, as demais não o são (LOMÔNACO, 1996, 2001).

Por fim, essas características definidoras do conceito estão necessariamente incluídas nos subconjuntos desse conceito. Exemplo: família tem necessariamente as características consanguinidade, colateralidade, parentesco, ao lado de suas características específicas (LOMÔNACO, 1996, 2001).

O engessamento causado por essa visão clássica ao ser transposto para a escola torna ainda mais evidente o conservadorismo familiar comumente impresso ao estabelecer como parâmetros de aprendizagem a procedência familiar, responsabilizando as novas estruturas familiares pelo desempenho escolar de seus alunos.

Carvalho (2000, 2004), Yunes; Garcia (2007) e Oliveira; Marinho Araújo (2010) fazem inferências à visão dos profissionais da educação relacionados à participação da família no processo de ensino-aprendizagem. Para os autores e autoras, educadores 
alegam que a família tem estado por detrás do sucesso e tem sido culpada pelo fracasso escolar, acusando as famílias pelas dificuldades ou sucesso dos estudantes, além de possuírem crenças pessimistas sobre as novas configurações familiares, que aliadas a outros aspectos, são caracterizadas como desorganizadas, desviantes e instáveis quando organizadas em modelos não convencionais.

Para Varani \& Silva (2010) estes educadores embora compreendam que a família seja fundamental no processo de desenvolvimento integral das crianças, não podem responsabilizá-la pelo desempenho escolar dos alunos baseado na sua composição, pois o bom ou o mau desempenho escolar não depende exclusivamente da sua estruturação. Outros inúmeros fatores (sociais, políticos, econômicos e culturais) influem no desempenho, bem como no sucesso ou no fracasso escolar dos alunos, inclusive o tipo de participação requerido de qualquer espécie de família.

No mais, esta concepção clássica de família incide negativamente no processo de integralização da escola e família, diretriz prevista como gestão democrática no Plano Nacional de Educação (BRASIL, 2014), ao convocar para participação os pais (termo genérico que define pais e mães) sem considerar

As relações de poder variáveis e de mão dupla, relações de classe, raça/etnia, gênero e idade que, combinadas, estruturam as interações entre essas instituições e seus agentes; A diversidade de arranjos familiares e as desvantagens materiais e culturais de uma parte considerável das famílias; As relações de gênero que estruturam as relações e a divisão de trabalho em casa e na escola (CARVALHO, 2004, p.42).

Consequentemente, estas estratégias expandem seu raio de ação para além dos muros da escola, formalizando as interações com a família, especificando seus papéis e contribuições para o sucesso escolar, "regulamentando as relações da família e escola de acordo com um modelo particular de participação dos pais/mães na escola: o de classe média, baseado na divisão de gênero tradicional" (CARVALHO, 2004, p.52).

A busca pela etimologia da palavra família também foi um dado constante na busca da conceituação da família.

O Grupo 01 e o Grupo 02 estabeleceram que: “[...] a palavra família prende-se ao verbete latino famulus, escravo, porém, em sua acepção original, família era evidentemente a família próprio iure, o grupo de pessoas efetivamente sujeitas ao poder do pater familias". 
A busca por conceitos nominais compreende aqueles que são estabelecidos por convenção social na forma de definições simples, nas quais são apresentadas suas propriedades necessárias e suficientes. São as que mais se aproximam da concepção clássica (LOMÔNACO, 1996, 2001).

Ambos os Grupos buscaram na jurisprudência a definição e caracterização de família:

Grupo 01: "família é definida como uma rede de pessoas consanguíneas e próximas ligadas por laços afetuosos. Entende-se então como família a junção de pessoas do mesmo sangue com grau de parentesco. Pai, mãe, filhos, irmãos, primos, tios, tias, sobrinhos, podendo ser considerados os laços afetuosos como critério para inclusão na família. Família é um conjunto de pessoas que possuem grau de parentesco entre si e vivem na mesma casa formando um lar. Uma família tradicional é normalmente formada pelo pai e mãe, e por um ou mais filhos".

Grupo 02: "O agrupamento formado pelas pessoas que, em razão de seus vínculos de parentesco ou sua qualidade de cônjuges, estão subsumidas à mesma comunidade de vida e onde os cônjuges assumem conjuntamente a direção moral $e$ material".

Novamente retoma-se a busca por conceitos nominais, estreitando os laços com a visão clássica de família. A nomeação estrita desconsidera que uma entidade familiar ultrapassa os limites da previsão jurídica, "para abarcar todo e qualquer agrupamento de pessoas onde permeie o elemento afeto, ou seja, onde deve-se reconhecer como família todo e qualquer grupo no qual os seus membros enxergam uns aos outros como seu familiar" (ALVES, 2007, p 330).

Para Oliveira \& Marinho Araújo (2010) e Alves (2007), mudanças no contorno familiar se deram com o advento da Constituição da República Federativa do Brasil (1988), que estabeleceu princípios fundamentais em relação a esse instituto e reconheceu como entidade familiar a união estável e a família monoparenteral, contrariando o Código Civil de 1916 que previa como status familia aqueles agrupamentos oriundos do instituto do matrimônio. "Foi somente a partir daí que o Estado, constitucionalmente, passou a dar proteção às famílias que não fossem constituídas pelo casamento" (PEREIRA, 2003 p. 08).

O Supremo Tribunal Federal em decisões históricas passou a legitimar como família, tanto em regulação como em direitos, aquelas constituídas por pessoas do mesmo sexo. 
Portanto, na contemporaneidade a família não pode ser definida apenas pelos laços de consanguinidade ou por aspectos legislativos, mas sim por um conjunto de variáveis, incluindo o significado das interações e relações entre as pessoas e das alterações sociais.

Dessa forma torna-se interessante observar que a dissolução de um modelo de família pode dar origem a outro, e vice-versa, ou que um núcleo familiar pode se enquadrar dentro das mais diversas espécies de família. Os laços de consanguinidade e as formas legais de união são apenas alguns atributos característicos da família, que associados ao grau de intimidade das relações, as formas de moradia, permitem a identificação de 196 tipos de famílias, produto de cinco subsistemas resultantes da concepção ecológica de micro, meso, exo, macro e cronossistema.

\begin{abstract}
Microssistema tem como base as relações diádicas, isto é, como os genitores interagem, com destaque para o grau de intimidade: se o estilo de vida é compartilhado ou separado, se esta relação é considerada heterossexual ou homossexual, se há alteridade no poder ou não. Já aquelas influências provenientes do mesossistema compreendem as relações com os filhos, ou seja, a sua presença ou ausência, se eles são biológicos ou adotivos e se moram com os pais ou não. No tocante ao exossistema do grupo familiar, esse engloba os contextos e as redes sociais que asseguram o sentimento de pertencer a um grupo especial, social ou cultural, tais como as relações mantidas por laços de consanguinidade ou casamento, vínculos de dependência ou autonomia financeira ou emocional. E o macrossistema reflete os valores e as crenças compartilhadas por um conjunto de pessoas, por exemplo, relacionadas ao fato de a união ser civil ou não, de a relação ser estável ou temporária, de os cônjuges habitarem ou não o mesmo espaço físico. E, por fim, o cronossistema diz respeito às transformações da família na sociedade, incluindo as suas diferentes configurações ao longo do tempo, dentre as quais a família extensa ou parenteral (PETZOAL, 1996 apud. DESSEN \& POLONIA, 2007, p.23).
\end{abstract}

Estudo realizado por Simón, Triana e Camacho (apud Rodrigo, Correa, 2004) na mesma linha de pesquisa buscando definir o conceito de família, com crianças em idade escolar, encontraram grandes diferenças entre as respostas dadas diante da tarefa de definir - "O que é uma família?" - e a tarefa de reconhecer - "Diga-me se são ou não uma família" - diferentes grupos de indivíduos que aparecem em episódios hipotéticos de acontecimentos cotidianos.

A primeira tarefa demanda um nível mais avançado de construção de conceito centrado na descrição do protótipo de família, por sua vez a segunda pode ser resolvida 
sem verbalizar, a partir da elaboração de modelos mentais baseados nos casos particulares que viram.

Ao levar em conta que mesmo antes do ingresso na escola a criança já possui um arcabouço de conhecimento informal, resultante do desenvolvimento "ontogenético a partir de suas experiências e que constitui o seu sistema de crenças sobre o mundo, a influenciar profundamente a obtenção do conhecimento formal, que se dará de forma planejada pela aprendizagem escolar" (NÉBIAS, 1999, p. 138), Rodrigo e Correa (2004) comprovaram que as crianças conseguiam verbalizar apenas uma dimensão de família, como membros, cuidados, afetos, pai, mãe, etc., recorrente em nossos resultados com sujeitos adultos, no entanto, as crianças eram capazes de reconhecer mais dimensões como mostra parte do estudo a seguir:

Pesquisador: O que é uma família?

Aluno: Um pai, uma mãe e um filho (dimensão, enumeração, membros);

Pesquisador: Miguel tem uma amiga chamada Petra. Quando Miguel está doente, Petra vai à sua casa e cuida dele. Quando Petra fica doente, Miguel vai à sua casa e cuida dela. Eles são uma família? Por quê?

Aluno: Sim, porque cuidam muito um do outro (dimensão cuidado).

Pesquisador: Jacinto e Verônica se gostam muito. Eles são uma família? Por quê?

Aluno: Sim, porque se gostam (dimensão afeto) (RODRIGO, CORREA, 2004, p. 89).

Corroborando com a pesquisa de Rodrigo, Correa (2004) questionamos a dificuldade em mudar determinados conceitos, arraigados na infância e que perpassam por toda a vida do indivíduo, e no caso dos sujeitos do nosso estudo, provavelmente refletirão em sua prática pedagógica.

\section{Em busca de uma integração efetiva entre famílias e escola}

Compreendemos o quão difícil é verbalizar um conceito social, e mesmo tendo utilizado ferramentas midiáticas, como a propaganda e a diversificação das estratégias didáticas, não conseguimos descaracterizar o caráter ideológico que permeia o conceito de família entre os estudantes de pedagogia, visto que as referidas campanhas em sua maior parte representavam modelos de família tradicional e que o tempo de quatro encontros não foram suficientes para romper ideias cristalizadas. 
Talvez, se tivéssemos problematizado o conceito de família na visão clássica com casos particulares de organização familiar teríamos obtido êxito em desmistificar a consanguinidade, colateralidade, descendência e reconhecimento legal como características definidoras do conceito de família.

Entendemos que o olhar da escola para a família precisa levar em conta os emaranhados de redes de interações que envolvem aspectos cognitivos, sociais, afetivos e culturais, a começar pelo professor, vítima de uma aprendizagem pela própria prática que não é facilmente abandonada pelas ciências, mas que através dela pode ser indagada e (re)configurada.

Para a efetividade das práticas pedagógicas na formação de conceitos de família, e quiçá para estudos futuros, tanto em jovens escolares como em universitários, podemos apontar fundamentados em Nébias (1999) algumas sugestões, tais como:

Ao trabalhar com tal conceito deve-se considerar as ideias prévias do aluno na construção de significados, visto que suas experiências iniciais não podem ser negadas, ao contrário, devem ser aceitas para progressivamente evoluírem, serem substituídas ou transformadas.

A partir do momento que o conceito de família trouxer maior satisfação, for significativo, fizer sentido e for útil, o conhecimento prévio do aluno e a resistência para reestruturá-lo acaba sendo superado.

O diálogo entre educador e educando propicia o diagnóstico das ideias que esses possuem sobre família, em vários momentos da aprendizagem. Da mesma forma, a interação entre pares e a observação dos diálogos travados entre eles possibilita novos olhares.

Provocar conflito no aluno com o fornecimento de contraexemplos de famílias organizadas em modelos não convencionais pode gerar dúvidas e insatisfação, levandoos a (re)analisarem suas concepções.

O professor carece saber que a simples nomeação das características essenciais e a repetição de definições de família não são garantias na formação de conceito, portanto, resolver problemas circunscritos na conceituação de família, devem ser estimulados, visto que propicia ao aluno considerar soluções alternativas para um mesmo conceito.

O educador enquanto mediador pode possibilitar que o aluno retome seu processo de trabalho, explicando suas ideias e analisando a evolução das mesmas. 
O docente ao desenvolver ações de inclusão possibilita ao aluno reconhecer as características necessárias ou suficientes para incluir ou não os sujeitos ao conceito de família.

Como nem todo conceito é passível de experimentação, é necessário que o educador reconheça e aplique em suas estratégias inclusivas o valor de meios variados, tais como: filmes, explorações de campo, etc.

Por fim, é válido ressaltar que o ensino sistemático e explícito na escola tem como princípio a (re)configuração do conceito de família e, principalmente, deverá desenvolver formas de pensar que se estendam para outras áreas e para situações cotidianas que transcendem a sala de aula.

\section{PARA NÃO CONCLUIR}

Os resultados obtidos neste estudo apontam que o conceito que estudantes do curso de pedagogia possuem sobre família possivelmente é sustentado na aprendizagem casual e/ou vivenciada em suas experiências práticas, e tal assimilação é uma barreira no convívio com a multiplicidade de famílias organizadas em modelos não convencionais com as quais firmarão parceria em sua atuação profissional.

A instituição familiar passou a refletir as mudanças históricas que ocorreram na sociedade, e no percurso destas evoluções se formaram novos núcleos familiares, distantes daqueles modelos de família considerados tradicionais, padronizados, determinando as entidades onde se predominam os aspectos sentimentais. A família contemporânea é caracterizada pela redefinição de papéis, socialização e desierarquização. Fatores que de forma isolada ou combinada permitem as mais diversas formas de organização familiar centradas na valorização da solidariedade, dignidade, ajuda mútua, colaboração, bem-estar coletivo e aspectos afetivos.

No entanto, desconsiderando estes aspectos, podemos observar em nosso estudo, que mesmo diante deste cenário em que a família se insere, a busca recorrente de nossos sujeitos em definir o conceito de famílias na visão clássica, ancorada nos conceitos elementares e na definição jurisprudencial, é uma ação que desconsidera as mais distintas formas de ser e estar família no século XXI. Tal aspecto em grande parte é fruto da cultura midiática, que tem na sociedade um público de consumo heteronormativo e um cliente patrocinador, que aspiram um ideário de família dentro 
dos moldes tradicionais, mesmo que possuam experiência pessoais distintas deste molde.

No entanto, não podemos culpabilizar os sujeitos da pesquisa pela não compreensão do conceito, visto que assumimos a mea-culpa, ao simplesmente solicitar a verbalização do conceito e não a sua problematização através de contraexemplos de forma a (re)configurar os conceitos preexistentes. Mesmo diante do uso de alguns recursos estratégicos como propagandas, o trabalho colaborativo e produção, a simples transmissão destes vídeos e a leitura de apenas um texto, não foram recursos suficientes para a ressignificação de conceitos prévios sobre família.

Outro aspecto impeditivo no aprofundamento da discussão refere-se à questão temporal e à abrangência de outros conceitos, como constituinte obrigatório da ementa do curso em questão.

Estes aspectos carecem ser levados em consideração ao se trabalhar a formação de conceitos de família em sala de aula. É precípua a necessidade em trabalhar os conceitos de forma profunda e não rasa, visto que o proposto não foi suficiente para desconstruir o conceito enraizado de família.

Problematizar a realidade das famílias é a palavra chave no processo formativo de qualquer sujeito, e a complexidade dos fatores que interferem no seu conceito requer que todos aqueles que pretendem defini-lo busquem refletir que ela deve ser compreendida historicamente e analisada em suas especificidades.

Para tanto, compete ao ensino sistematizado na escola prever como princípio a (re)configuração do conceito de família, mesmo diante da sistematização da indústria cultural, cujo conceito traduz-se em uma visão clássica de família, e, principalmente, deverá desenvolver formas de pensar que se estendam a situações corriqueira que transcendem a sala de aula, pois somente assim preconceitos, estereótipos, idealizações serão reconhecidos e afastados das práticas pedagógicas traduzindo-se em uma sociedade mais equânime e respeitosa.

\section{REFERÊNCIAS}

ALVES, Leonardo Barreto Moreira. O Reconhecimento Legal do Conceito Moderno de Família: O Art. 5º II e Parágrafo Único, da Lei No 11.340/2006 (Lei Maria Da Penha). De jure: Revista Jurídica do Ministério Público do Estado de Minas Gerais, Belo Horizonte, n.8, p.329-34, jan./jun, 2007. 
BOURDIEU, Pierre. O poder simbólico. TOMAZ, Fernando (Trad.). Ed. Bertrand Brasil. Rio de Janeiro, 1989.

BOURDIEU, Pierre. Questões de Socilologia. PEREIRA, Miguel Serras (Trad.). Fim de Século, Lisboa, 2003.

BRANDÃO, Zaia. CANEDO, Maria Luiza. XAVIER, Alice. Construção solidária do habitusescolar: resultados de uma investigação nos setores público e privado. Revista Brasileira de Educação, v. 17, n. 49 jan.-abr. 2012.

BRASIL. Lei no 13.005, de 25 de junho de 2014. Brasília: 2014. Disponível em: $<$ http://www2.camara.leg.br/legin/fed/lei/2014/lei-13005-25-junho-2014-778970publicacaooriginal-144468-pl.html>. Acesso em: 05 nov. 2014.

CARVALHO, Maria Eulina Pessoa de. Modos de educação, gênero e relações escolafamília. Cadernos de Pesquisa, v. 34, n. 121, p. 41-58, jan./abr.2004.

CARVALHO, Maria Eulina Pessoa de. Relações entre a família e escola e suas implicações de gênero. Cadernos de Pesquisa, n 110, p. 143-155. julho/2000.

DESSEN, Maria Auxiliadora; POLONIA, Ana da Costa. A família e a escola como contextos de desenvolvimento humano. Paidéia, 2007.

HINTZ, Helena Centeno. Novos tempos, novas famílias? Da modernidade à pósmodernidade. Pensando famílias. p.8-19, 2001.

HIRONAKA, G. M. F. N. Família e Casamento em Evolução. In: Revista Brasileira de Direito de Família, Porto Alegre, nº 1, abr.jun. 1999.

LARA, A. M. B. MOLINA, A.A. Pesquisa qualitativa: apontamentos, conceitos e tipologias. In: TOLEDO, C. C. A. GONZAGS, M. T. C. (Org.). Metodologia e técnicas de pesquisa: nas áreas de ciências humanas. Maringá: Eduem, 2011.

LOMÔNACO, J. F. B et al. Do característico ao definidor: um estudo exploratório sobre o desenvolvimento de conceitos. Estudos de Psicologia. Jan-abr 1996. Vol. 12 n1.

MELLO, Sílvia Leser de. A violência urbana e a exclusão dos jovens. In: SAWAIA, B. (Org.). As artimanhas da exclusão: análise psicossocial e ética da desigualdade social. Ed. Vozes, 2001.

NÉBIAS, Cleide. Formação dos conceitos científicos e práticas pedagógicas. Interface - Comunic, Saúde, Educ 4, fev/1999.

OLIVEIRA JR, Isaias B. de. MAIO, Eliane Rose. Família e escola: um novo (re) pensar e (re) agir pedagógico. Revista LABOR. n 10, v.1, 2013.

OLIVEIRA JR, Isaias B. de. MAIO, Eliane Rose. Kit Gay: “dá para continuar discutindo esse assunto? Revista Latino-americana de Geografia e Gênero, Ponta Grossa,v. 5, n. 1 ,jan. / jul. 2014. 
OLIVEIRA, Cynthia Bisinoto Evangelista de; MARINHO ARAÚJO, Claisy Maria. A relação família-escola: intersecções e desafios. Estudos de Psicologia. Campinas. p. 99-108, janeiro-março. 2010.

PEREIRA, Rodrigo da Cunha. Direito de família: uma abordagem psicanalítica. $2^{\mathrm{a}}$. ed. rev. atual. ampl. Belo Horizonte: Del Rey, 2003.

RODRIGO, MariaJosé.; CORREA, Nieves. Representações e processos cognitivos: esquemas e modelos mentais. In: COLL, C; MARCHESI, A.; PALACIOS, J. [Org.] Desenvolvimento psicológico e educação. Vol. 2. $2^{\mathrm{a}}$ ed. Tradução de Fátima Murad. Porto Alegre: Artmed, 2004.

SETTON, Maria da Graça Jacintho. Família, escola e mídia: um campo com novas configurações. Educação e Pesquisa, São Paulo, v.28, n.1, p. 107-116, jan./jun. 2002ª .

SETTON, Maria da Graça Jacintho. A teoria do habitus em Pierre Bourdieu: uma leitura contemporânea. Revista Brasileira de Educação. n. 20, Mai./Jun./Jul./Ago. 2002b.

VARANI, A. SILVA, D. C. R. A relação família-escola: implicações no desempenho escolar dos alunos dos anos iniciais do ensino fundamental. R. Bras. Est. Pedag., Brasília, v. 91, n. 229, set./dez. 2010.

YUNES, Maria Angela Mattar; GARCIA, Narjara Mendes; ALBUQUERQUE, Beatriz de Mello. Monoparentalidade, pobreza e resiliência: entre as crenças dos profissionais e as possibilidades da convivência familiar.Psicol. Reflex. Crit., vol.20, n.3. 2007.

\section{Como referenciar este artigo}

OLIVEIRA JÚNIOR, Isaias Batista de.; MORAES, Dirce Aparecida Foletto de.; COIMBRA, Renata Maria. A indústria cultural e a des/re/construção das estereotipias de famílias na formação de conceitos docentes. Revista Ibero-Americana de Estudos em Educação, Araraquara, v. 11, n. 4, p. 2012-2019, 2016. Disponível em: <http://dx.doi.org/10.21723/riaee.v11.n4.7723 >. E-ISSN: 1982-5587.

Submissão em: abril/2015

Aprovação final em: dezembro/2016 